\title{
Outcomes of antenatally detected renal pelvic dilatation: A retrospective study
}

\author{
M C G Karunanayake ${ }^{1}$, Jasper van der Westhuyzen², Apaks Dede ${ }^{3}$
}

Sri Lanka Journal of Child Health, 2009:38: 89-91

(Key words: renal pelvic dilatation, antenatal, postnatal outcome)

\begin{abstract}
Background Renal pelvic dilatation is one of the abnormalities detected antenatally by ultrasound scan (USS), incidence being around $0.5-1 \%$ of live births. In most children it is benign.
\end{abstract}

Objectives To determine the local occurrence and outcomes of antenatally detected renal pelvic dilatation and to determine whether there is a sex difference in the incidence and outcomes

Method The 18-20 weeks morphology scans of all live newborn babies delivered in the maternity ward of Hervey Bay hospital from 01/02/2008 to $30 / 09 / 2008$ were retrospectively analysed. Infants with antenatally detected renal pelvic dilatation were followed up with 2 weeks postnatal USS. Infants with increasing pelvic dilatation or persistent moderate to severe dilatation were followed up with MCUG / MAG 3 scan.

Results Total number of live births during the 8 month period was 695 . There were 362 males and 333 females. There were $15(2.2 \%)$ neonates (7 male, 8 female) with antenatally detected renal pelvic dilatation. Occurrence in males was $1.9 \%$ and females $2.4 \%(p=0.671)$. Five cases were bilateral and 10 unilateral. In unilateral cases, left side involvement was more common (60\%). In bilateral cases left side involvement was more severe in $60 \%$. There were $9(60 \%)$ cases with mild dilatation, $4(27 \%)$ with moderate dilatation and 2 $(13 \%)$ with severe dilatation. Oligohydramnios, thickened bladder or dilated ureters were not detected in any of the cases. Caliectasis was detected in 2 infants (13.3\%) who had severe dilatation in antenatal scan. Subsequent postnatal scan was completely normal in $6(40 \%)$, improved in $\operatorname{six}(40 \%)$ and worse in three $(20 \%)$. There

${ }^{1}$ Principal House Officer, Hervey Bay Hospital,

${ }^{2}$ Director of Paediatrics, Fraser Coast Health Service District, ${ }^{3}$ Consultant Paediatrician, Hervey Bay Hospital, Australia

(Received on 17 November 2008. Accepted on 29 January 2009) were 4 cases with mild, 2 with moderate and 3 with severe dilatation. All infants with severe dilatation had caliectasis. MCUG was done in 3 infants but did not detect any abnormality or reflux. Antibiotic prophylaxis was stopped after normal MCUG. MAG 3 scan was done in 3 infants including one with normal MCUG and all three detected PUJ obstructions but none required surgery. All 3 infants with PUJ obstruction had either severe (2) or moderate (1) dilatation on antenatal scan and all 3 had severe dilatation on postnatal scan. Of these 3 infants with PUJ obstruction, 2 had caliectasis in antenatal scan and all 3 had caliectasis in the subsequent postnatal scan. Follow up period varied from 1 to 9 months. None developed symptomatic UTI during this period.

Conclusions There were $2.2 \%$ neonates with antenatally detected renal pelvic dilatation. Outcome was satisfactory in $80 \%$ of cases. There was no significant sex difference in occurrence or outcome.

\section{Background}

Renal pelvic dilatation is an abnormality detected antenatally by ultrasound scan (USS), incidence being around $0.5-1 \%$ of live births. However, in most children the condition is benign. Only in the minority is it associated with significant renal diseases such as posterior urethral valves (PUV) and pelvi-ureteric junction (PUJ) obstruction which require later surgery and long term follow up. Vesicoureteric reflux (VUR) is more common and benefits of early detection are not clear in asymptomatic patients ${ }^{1,2,3}$. With improvement of ultrasound equipment over recent years and wider access to routine ultrasound examinations antenatally the number of children diagnosed with mild renal pelvic dilatation has increased ${ }^{1,2,3}$.

\section{Objectives}

- To determine the local occurrence and outcomes of antenatally detected renal pelvic dilatation. 
- To determine whether there is a sex difference in its occurrence and out comes.

\section{Method}

All live newborn babies delivered in the maternity ward of Hervey Bay hospital from 01/02/2008 to 30/09/2008 (eight months) with 18-20 weeks morphology ultrasound scan (USS) were retrospectively analysed. Any hydronephrosis detected was graded according to the maximum antero-posterior diameter of the renal pelvis at 18 20 weeks $(0-4 \mathrm{~mm}$ normal, $5-9 \mathrm{~mm}$ mild, $10-15 \mathrm{~mm}$ moderate, $>15 \mathrm{~mm}$ severe). This classification was used for both the antenatal (18-20 weeks) and postnatal (1-2 weeks) scans. Infants with antenatally detected renal pelvic dilatation were followed up in 2 weeks with postnatal USS. Infants with increasing pelvic dilatation or persistent moderate to severe dilatation, even though improved on the repeat USS, were followed up with micturating cystourethrography (MCUG) / technetium-99m-mercaptoacetyltriglycine (MAG 3) scan.

Z-score was used to analyse the statistical significance between occurrence of renal pelvic dilatation in males and females.

\section{Ethical clearance}

According to Queensland Health Hospital Guidelines ethical clearance is not needed for this type of study. Permission from heads of departments of Obstetrics \& Gynaecology, and Paediatrics was obtained.

\section{Results}

Total number of live births during the period of 8 months was 695. There were 362 males and 333 females. There were $15(2.2 \%)$ neonates ( 7 male, 8 female) with antenatally detected renal pelvic dilatation. Occurrence was $1.9 \%$ in males and $2.4 \%$ in females. This was not statistically significant $(\mathrm{p}$ $=0.671$ ). There were 5 bilateral and 10 unilateral cases. In unilateral cases left side involvement was more common $(60 \%)$. In bilateral cases left side involvement was more severe in $60 \%$ and right side involvement was more severe in the balance. There were $9(60 \%)$ cases with mild dilatation, $4(27 \%)$ with moderate dilatation and $2(13 \%)$ with severe dilatation. Oligohydramnios, thickened bladder or dilated ureters were not detected in any of the cases. Caliectasis was detected in the 2 infants $(13.3 \%)$ with severe dilatation.

Subsequent postnatal USS, performed around 7-10 days of life, were completely normal in $6(40 \%)$, improved in $6(40 \%)$ and worse in $3(20 \%)$. In the 9 with abnormalities, 4 were cases of mild, 2 with moderate and 3 with severe dilatation. All infants with severe dilatation had caliectasis. MCUG was performed in these 3 infants but did not detect any abnormality or reflux. Antibiotic prophylaxis was stopped after normal MCUG. MAG 3 scan was performed in 3 infants whose USSs were highly suggestive of pelvi-ureteric junction (PUJ) obstruction, including one with normal MCUG. All 3 were confirmed to have PUJ obstructions but none required surgery. All 3 infants with PUJ obstruction had either severe (2) or moderate (1) dilatation on antenatal scan and all 3 had severe dilatation on postnatal scan. Of these infants with PUJ obstruction, 2 had caliectasis on antenatal scan and all 3 had caliectasis on subsequent postnatal scan. Follow up period varied from 1 to 9 months (Table 1). None developed symptomatic urinary tract infection during this period.

Table 1

Period of follow up

\begin{tabular}{|c|c|}
\hline No. Of months & No. of patients \\
\hline Up to 3 months & 3 \\
\hline $4-6$ months & 5 \\
\hline $7-9$ months & 7 \\
\hline
\end{tabular}

\section{Discussion}

Dilatation of the renal pelvis, detected by antenatal scan, has an incidence of $0.5-1 \%$ of total live births in most studies ${ }^{1,2,3,4,5}$. However, in our sample the occurrence was comparatively higher (2.2\%). Many congenital anomalies causing hydronephrosis are significantly associated with the male $\operatorname{sex}^{5,6}$. In this study male to female ratio in antenatally detected renal pelvic dilatation was 1:1.1. Only abnormality detected in our study was PUJ obstruction (3) and of them 2 were male and one was female (2:1). Despite the higher incidence of antenatally detected hydronephrosis in boys, other studies did not demonstrate a statistically significant difference in outcome between girls and boys $^{3,5}$. In fact, in our study occurrence in females was higher than in males $(1.9 \%$ vs. $2.4 \%)$, but this difference was not statistically significant $(p=0.671)$. It also failed to demonstrate any difference in outcome.

As demonstrated in other studies, greater the degree of antenatal dilatation greater the risk of significant postnatal pathology 5,6 . Most mild to moderate prenatal dilatation of renal pelvis resolve without any complications. Presence of thickened bladder, dilated ureters, caliectasis and renal parenchymal cysts are associated with a poor outcome , $^{1,3,5}$. Presence of bilateral involvement itself is not a poor prognostic factor ${ }^{3}$. Our findings are similar. 
Vesicoureteric reflux (VUR) is the commonest abnormality detected in both studies which had nonselective approach ${ }^{1,2,4,5}$ as well as selective approach $^{3,7}$ to do MCUG. This differs from our study which detected 3 cases with PUJ obstruction. We have chosen the selective approach as MCUG is an invasive procedure requiring urethral catheterization, involving radiation, and as such cannot be justified in all patients ${ }^{3,7,8,9}$. Undoubtedly some cases of VUR in this study population were missed, but it has been shown that VUR is also present in infants with nondilated systems antenatally ${ }^{10,11,12}$. The significance of VUR in the asymptomatic population has not been established. Minor and sometimes major, degrees of VUR often resolve spontaneously ${ }^{9,12}$. We have started prophylaxis for all neonates with moderate to severe dilatation, but only 3 demonstrated significant abnormalities. Other studies recommend starting antibiotics at birth only for cases with severe dilatation or cases with other poor prognostic factors $^{1,3,5}$ as isolated renal pelvic dilatation (mild to moderate) often resolves spontaneously with time $\mathrm{e}^{1,5}$. Although we have started antibiotics in all cases with moderate to severe dilatation at birth, only one case which had moderate dilatation in antenatal scan progressed to severe dilatation after birth. All others (3 cases) showed improvement on postnatal scan. Our study population was comparatively small and this may be the reason for not detecting some of the other abnormalities.

This study resulted in a change in the protocol of management of antenatally detected renal pelvic dilatation in Hervey Bay hospital. Now we start prophylactic antibiotics at birth only in severe cases $(>15 \mathrm{~mm})$ and MCUG is restricted to cases with poor prognostic factors in USS.

\section{Conclusions and recommendations}

- Occurrence of antenatally detected renal pelvic dilatation in our study was $2.2 \%$ of total live births.

- Outcome was satisfactory in $80 \%$ of cases.

- Presence of caliectasis in antenatal or post natal scans was associated with adverse outcomes.

- There was no significant sex difference in occurrence or outcome.

- A selective approach for MCUG is recommended.

\section{References}

1. Dudley JA, Frank JD, Tizard EJ, Haworth JM, MCGraw ME. Clinical relevance and implications of antenatal hydronephrosis Archives of Disease in Childhood Fetal \& Neonatal Edition 1997; 76:f31-f32.
2. Owen RJT, Lamont AC, Brooks J. Early management and investigation of prenatally diagnosed hydronephrosis. Clinical Radiology 1996; 51: 173-6.

3. Duncan KA. Antenatal renal pelvic dilatation; the long term outlook Clinical Radiology 2007; 62 (2), 134-9.

4. Jaswon MS, Dibble L, Puri S, Davis J, Young J, et al. Archives of Disease in Childhood Fetal \&Neonatal Edition 1999; 80:f135-138

5. ChengVernique Phan AM, Gearg DF, Rosenbium ND. Outcome of isolated antenatal hydronephrosis. Archives of Paediatrics \& Adolescent Medicine 2004; 158: $38-40$.

6. Ja R, Diamond DA. Prenatal hydronephrosis. Current Opinion in Paediatrics 2001:13:138-41.

7. Kapadia H, Erasmile KU, Pilo C. Antenatal renal pelvic dilatation emphasising vesicoureteric reflux: Two year follow up of minor postnatal dilatation. Acta Paediatrica 2007; 93 (3), 336-9.

8. Harding LJ, Malone PSJ, Gwellosley D. Antenatal minimal hydronephrosis; is its follow up an unnecessary cause of concern? Prenatal Diagnosis 1999; 19:701-5.

9. Gunn TR, Mora JD, Pease P. Antenatal diagnosis of urinary tract abnormalities by ultrasonography after 28 weeks gestation: incidence and outcome. American Journal of Obstetrics \& Gynaecology 1995;172 (2): 479-86.

10. Elder JS, Importance of antenatal diagnosis of vesicoureteric reflux. Journal of Urology 1992; 148: 1743-5.

11. Burge DM, Griffiths MD, Malore PS. Foetal vesicoureteric reflux: Outcome following conservative postnatal management. Journal of. Urology 1992; 148: $1743-5$.

12. Crabbe DC, Thomus DF, Gordon AC, et al, Use of $99 \mathrm{~m}$ technetium-dimercapto succunic acid to study patter of renal damage associated with prenatally detected vesicoureteric reflux. Journal of Urology 1992; 148: 1229-31. 
